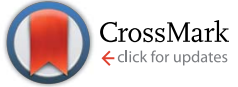

Cite this: RSC Adv., 2017, 7, 14053

Received 12th December 2016 Accepted 22nd February 2017

DOI: 10.1039/c6ra28106k

rsc.li/rsc-advances

\title{
Leaching of fluorine and rare earths from bastnaesite calcined with aluminum hydroxide and the recovery of fluorine as cryolite
}

\begin{abstract}
Jingui He, ${ }^{\text {ab }}$ Yong $\mathrm{Li}^{\mathrm{a}}{ }^{\text {Xiangxin Xue, }}{ }^{\text {*a }}$ Hongqiang $\mathrm{Ru}^{\mathrm{b}}$ Xiaowei Huang ${ }^{\mathrm{c}}$ and $\mathrm{He} \mathrm{Yang}^{\mathrm{a}}$
In order to avoid fluorine loss and contamination, and recover the fluorine resource in bastnaesite, a new process of decomposing bastnaesite with aluminum hydroxide followed by sulfuric acid leaching was proposed. The calcination mechanism was discussed by TG-DSC and XRD analyses. Fluorine could be taken up by $\mathrm{Al}_{2} \mathrm{O}_{3}$, and the discharge of fluorine was prevented. Leaching from calcined ore was achieved with dilute sulfuric acid, and the parameters affecting the leaching rates of fluorine and rare earths (REs) were investigated. It shows that the leaching rates of $\mathrm{F}, \mathrm{Ce}$ and total RE of $92.71 \%, 98.92 \%$ and $98.61 \%$ could be obtained under the conditions of $n(\mathrm{Al}) / n(\mathrm{~F}) 1 / 2$, calcination temperature $500{ }^{\circ} \mathrm{C}$, calcination time $1 \mathrm{~h}$, sulfuric acid concentration $3 \mathrm{~mol} \mathrm{~L}-1$, leaching temperature $90{ }^{\circ} \mathrm{C}$ and leaching time $1 \mathrm{~h}$. Fluorine could be separated from REs after extraction, and was recovered as $\mathrm{Na}_{3} \mathrm{AlF}_{6}$ with the recovery rates of fluoride and aluminum greater than $96 \%$ XRD and SEM analyses indicated that the monoclinic phase cryolite was obtained.
\end{abstract}

\section{Introduction}

Bastnaesite constitutes one of the principal rare earth minerals of light rare earths in China with the chemical formula $\mathrm{RECO}_{3} \mathrm{~F}$ or $\mathrm{RE}_{2}\left(\mathrm{CO}_{3}\right)_{3} \cdot \mathrm{REF}_{3} \quad(\mathrm{RE}=$ rare earth), which theoretically contains $50 \%$ cerium, $0.2-0.3 \%$ thorium and $8-10 \%$ fluorine, etc. $^{\mathbf{1 - 3}}$ It is mainly distributed in Baiyunebo of Inner Mongolia, Mianning of Sichuan Province and Weishan of Shandong Province. ${ }^{4}$ A series of efficient hydrometallurgical technologies have been developed to process bastnaesite. At present, the main methods for processing bastnaesite in industry include a concentrated hydrochloric acid leaching-alkali conversion method, oxidation calcination-acid leaching method, etc. The concentrated hydrochloric acid leaching-alkali conversion method is used to produce $\mathrm{CeO}_{2}$ and less-Ce mixed RE chloride. This method is unfriendly to the environment due to the volatilization of concentrated hydrochloric acid solution and the discharge of fluorine and the radioactive element thorium. The oxidation calcination-hydrochloric acid leaching method is commonly used for the smelting of bastnaesite by rare earth enterprises. ${ }^{5}$ During the calcination process, bastnaesite can be broken down into rare earth oxides and rare earth oxyfluorides,

${ }^{a}$ School of Metallurgy, Northeastern University, Shenyang, Liaoning 110819, China. E-mail: xuexx@mail.neu.edu.cn; Xue_Xiangxin@126.com

${ }^{b}$ School of Material Science and Engineering, Northeastern University, Shenyang, Liaoning 110819, China

${ }^{c}$ National Engineering Research Center for Rare Earth Materials, General Research Institute for Nonferrous Metals and Grirem Advanced Materials Co., Ltd., Beijing 100088, China and the $\mathrm{Ce}^{3+}$ is mostly oxidized to $\mathrm{Ce}^{4+}$. The $\mathrm{Ce}^{4+}$ can be separated from the other $\mathrm{RE}^{3+}$ when hydrochloric acid is used to leach calcined ore. The leaching residue rich in $\mathrm{Ce}^{4+}$ can be collected and used to produce high-purity cerium products. However, this method has many shortcomings such as discharge of fluorine-containing wastewater, low rare earth recovery, serious environmental pollution and long process flow. ${ }^{6}$ The oxidation calcination-sulfuric acid leaching-solvent extraction process can recover most of the rare earths and bearing valuable elements, and has rapid dissolution speed and high leaching rate, making it a more advanced technology for smelting of bastnaesite. ${ }^{7-9}$ However, some issues still remain resulting from the existence of $8-10 \%$ fluorine. Some of fluorine escapes as hydrogen fluoride gas from the decomposition of bastnaesite in the oxidation calcination process as well as in the leaching process, and also part of fluorine is left in the residue as insoluble fluorides in the sulfuric acid leaching process. ${ }^{4,10}$ In recent years, annual treated quantity of bastnaesite was about 22500 tons, thus, a great quantity of fluorine was produced and discharged into the environment, which will lead to serious pollution of surface and ground water. ${ }^{11}$ Fluoride has been listed as one of the contaminants in water by the World Health Organization (WHO), which will cause many problems in human health. Therefore, fluorine contamination is considered as a serious pollution worldwide. ${ }^{12}$ Fluorine is also an important strategic resource, thus, the discharge of such waste is a waste of fluorine resource. After leached by sulfuric acid, fluoride mainly exists as $\left[\mathrm{CeF}_{2}\right]^{2+}$ in leaching solution, which makes it difficult to separate $\mathrm{F}^{-}$and $\mathrm{Ce}^{4+}$, leading to the formation of the third phase in the extraction of rare earths. ${ }^{13-15}$ Considering the 
problems caused by fluorine, some new defluorination smelting technologies of bastnaesite have been explored, such as $\mathrm{NH}_{4} \mathrm{Cl}$ roasting method, ${ }^{16} \mathrm{Na}_{2} \mathrm{CO}_{3}$ roasting method ${ }^{17}$ and CaO roasting method. ${ }^{4}$ However, these methods have their own shortcomings, such as multiple washing and solid-liquid separation steps, production of large amount of fluoride-containing wastewater and residue which are difficult to treatment, large energy consuming and high investment; therefore, they are rarely applied in industrial production. Wang et al. ${ }^{18}$ invented a new method to recover fluorine. Firstly fluoride was extracted into the organic phase as $\left[\mathrm{CeF}_{2}\right]^{2+}$, then the strip liquor containing aluminum salt was utilized to scrub fluoride from the $\mathrm{F}^{-}$and $\mathrm{Ce}^{4+}$ loaded organic phase. This technology does not involve the elimination and recycling of discharged hydrogen fluoride waste gas in the oxidation calcination and leaching processes as well as the recovery of insoluble fluorides in bastnaesite. In addition, some $\mathrm{Al}^{3+}$ will enter into the organic phase, resulting in a substantial organic consumption.

Fluoride is considered as a hard base because of the small ionic size and high electronegativity, which possesses a strong affinity for metal ions such as $\mathrm{Al}^{3+}, \mathrm{B}^{3+}$ and $\mathrm{Fe}^{3+}$. Our lab has conducted the exploration of using boron salts and aluminum salts as defluoridation reagent in fluoride-bearing rare earths sulfate solution. ${ }^{19}$ To solve the problems of fluorine loss and contamination, and recover the fluorine resource in bastnaesite, a new process of decomposing bastnaesite with aluminum hydroxide was proposed in this study. The discharge of fluorine can be prevented by converting the fluorine into aluminum fluoride. Leaching for calcined ore was performed with dilute sulfuric acid. Then, the rare earths in the leaching solution were extracted by di-(2-ethylhexyl) phosphoric acid (HDEHP), and the raffinate containing aluminum fluoride was used to recover fluorine as cryolite $\left(\mathrm{Na}_{3} \mathrm{AlF}_{6}\right)$. The cryolite is an essential chemical material and is widely used in industry, particularly in the Hall-Héroult process (a process for aluminum production). ${ }^{20}$ This paper aims to avoid the fluorine pollution through reducing the discharge of waste containing fluorine, recover the fluorine resource in bastnaesite and eliminate the negative influence of fluorine on the extraction of rare earths.

\section{Experimental}

\subsection{Materials and apparatus}

All reagents and organic solvents used were of analytical grade. Aluminum hydroxide, sodium fluoride, sodium hydroxide etc. were supplied by Guoyao Group Chemical Reagent Shenyang Co., Ltd. The sulfuric acid (98\%) was supplied by Shenyang Laibo Kemao Co., Ltd. HDEHP and kerosene were supplied by Shanghai Rare-earth Chemical Co., Ltd. and used without further purification. The bastnaesite samples used were obtained from Mianning mine of Sichuan Province in China. The chemical compositions are given in Tables 1 and 2 .

WLS-5 rapid intelligent muffle furnace (Hebi Tianhong Instrument Co., Ltd.) was utilized to conduct calcination experiments. ZXS100e X-ray fluorescence spectrometer (XRF) (Rigaku) was utilized to detect the compositions of samples. PW3040/60 X-ray diffraction (XRD) instrument (Panalytical) was
Table 1 The main chemical composition of bastnaesite (wt\%)

\begin{tabular}{llllllll}
\hline Component & $\mathrm{RE}_{x} \mathrm{O}_{y}$ & $\mathrm{~F}$ & $\mathrm{CaO}$ & $\mathrm{SrO}$ & $\mathrm{Fe}_{2} \mathrm{O}_{3}$ & $\mathrm{BaO}$ & $\mathrm{SiO}_{2}$ \\
Content/\% & 62.22 & 8.92 & 7.29 & 6.43 & 5.42 & 3.75 & 1.79 \\
\hline
\end{tabular}

utilized to determine the phase composition of samples in the $2 \theta$ of $10-80^{\circ}$ with $\mathrm{Cu} \mathrm{K} \alpha$ radiation, at a scan speed of $4^{\circ} \mathrm{min}^{-1}$ and a step size of $0.02^{\circ}$. SDT 2960 thermal analyzer (TA instruments) was utilized to measure the differential heat flow (DSC) and mass loss (TG) of bastnaesite samples in the temperature range from room temperature to $1000{ }^{\circ} \mathrm{C}$ with a heating speed of $10{ }^{\circ} \mathrm{C} \mathrm{min}^{-1}$ under air atmosphere. S-3400N scanning electron microscope (SEM) (Hitachi) was utilized to detect the surface morphology of the product. PXSJ-216 ion meter connected with a fluoride ion selective electrode and saturated calomel electrode (Shanghai Precision \& Scientific Instrument Co., Ltd.) was utilized to detect the concentration of fluoride.

\subsection{Experimental processes}

Firstly, $10 \mathrm{~g}$ of bastnaesite concentrate was mixed with a certain amount of aluminum hydroxide homogeneously in a porcelain boat, and then the mixed minerals were put into a muffle furnace and calcined for a predetermined temperature and time. Secondly, the calcined ore was leached by sulfuric acid at the liquid-solid mass ratio of 10 with stirring and heating for a certain period of time. After filtered, the leaching liquid and residue were obtained. The leaching residue was washed several times with deionized water, and dried in an oven at $100{ }^{\circ} \mathrm{C}$, then ground for detection. Thirdly, the HDEHP diluted with kerosene to the required concentration was used as extractant. The extraction of rare earths was performed by mixing equal volumes of leaching liquid and extractant in a separating funnel for $20 \mathrm{~min}$ by a mechanical stirrer. After two-phase separation, the raffinate was analyzed. Finally, the raffinate containing aluminum fluoride complexes was used to recover fluorine by producing cryolite. The sodium fluoride was added to adjust the $\mathrm{F} / \mathrm{Al}$ and $\mathrm{Na} / \mathrm{Al}$ molar ratios, and the sodium hydroxide or ammonia was used to adjust the $\mathrm{pH}$. After precipitation, the cryolite product was filtered and washed several times with deionized water, then dried for $3 \mathrm{~h}$ at $100{ }^{\circ} \mathrm{C}$. The supernatant solution was analyzed.

\subsection{Analyses}

The contents of related elements in the bastnaesite or leaching residue samples were analyzed by XRF method. The concentration of $\mathrm{Ce}^{4+}$ was determined by titration with standard $\left(\mathrm{NH}_{4}\right)_{2} \mathrm{Fe}\left(\mathrm{SO}_{4}\right)_{2}$ solution using sodium diphenylamine sulfonate as indicator. The concentration of $\mathrm{RE}^{3+}$ was determined by titration with standard EDTA solution using xylenol orange as

Table 2 The main RE distribution of bastnaesite (wt\%)

\begin{tabular}{llllll}
\hline Component & $\mathrm{CeO}_{2}$ & $\mathrm{La}_{2} \mathrm{O}_{3}$ & $\mathrm{Nd}_{2} \mathrm{O}_{3}$ & $\mathrm{Pr}_{6} \mathrm{O}_{11}$ & $\mathrm{Sm}_{2} \mathrm{O}_{3}$ \\
Content/\% & 31.51 & 23.33 & 5.26 & 1.92 & 0.23
\end{tabular}


indicator. The concentration of $\mathrm{Al}^{3+}$ was determined by EDTA reverse titration with standard zinc solution using xylenol orange as indicator. The concentration of $\mathrm{F}^{-}$was determined by fluoride ion selective electrode, and the ionic strength and the $\mathrm{pH}$ were maintained with total ionic strength adjusting buffer (TISAB).

The leaching rates of $\mathrm{F}$, Ce and total RE were calculated as following formula:

$$
\eta_{\mathrm{i}}(\%)=\frac{C_{\mathrm{i}} V}{m w_{\mathrm{i}}} \times 100
$$

where $\eta_{\mathrm{i}}$ is the leaching rates of $\mathrm{F}$, Ce and total RE, \%; $C_{\mathrm{i}}$ is the concentration of various elements in the leaching solution, $\mathrm{g}$ $\mathrm{L}^{-1} ; V$ is the volume of the leaching solution, $L ; m$ is the mass of bastnaesite concentrate, $g ; w_{\mathrm{i}}$ is the content of various elements in bastnaesite concentrate, $\%$.

\section{Results and discussion}

\subsection{TG-DSC and XRD analyses of bastnaesite}

In order to study the decomposition process of bastnaesite concentrate calcined with aluminum hydroxide and the decomposition temperature range, the TG-DSC analysis was carried out, and the results are shown in Fig. 1. As shown in Fig. 1(a), the endothermic peak appeared in the range of 420-
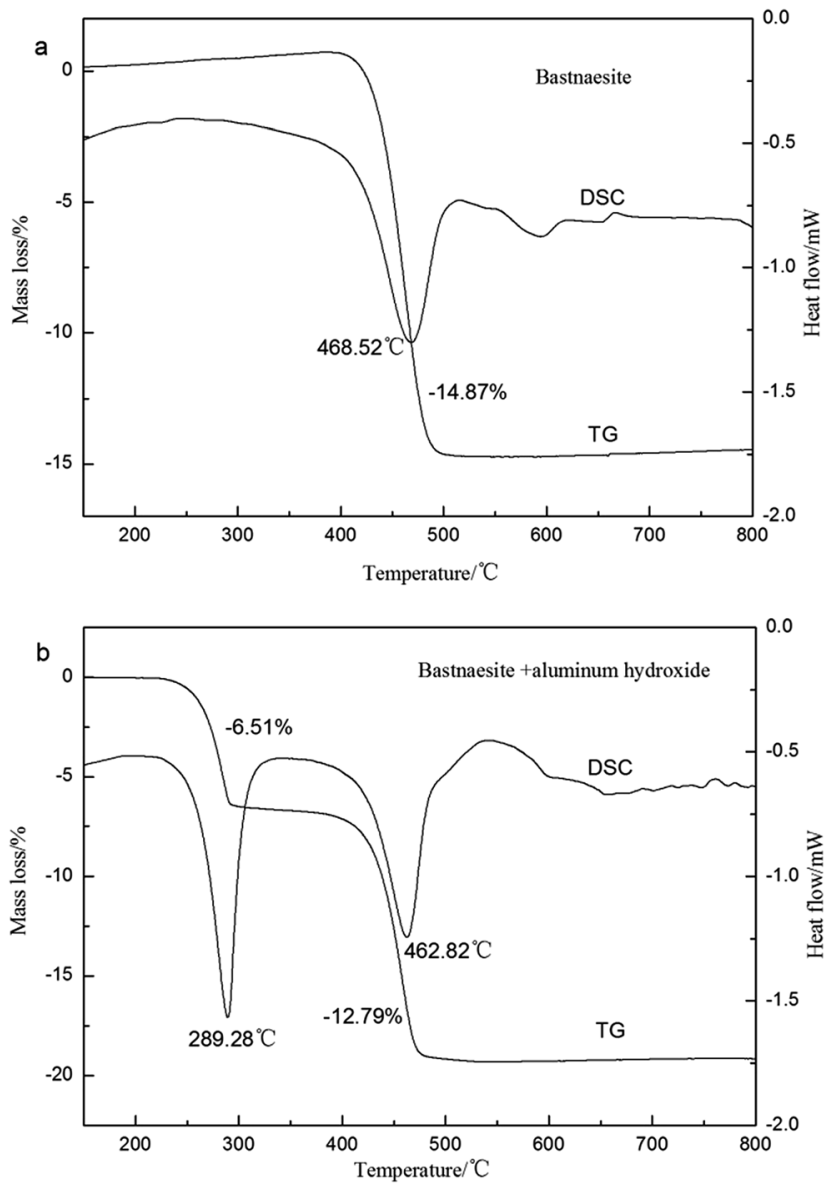

Fig. 1 TG-DSC curves of bastnaesite samples in the air.

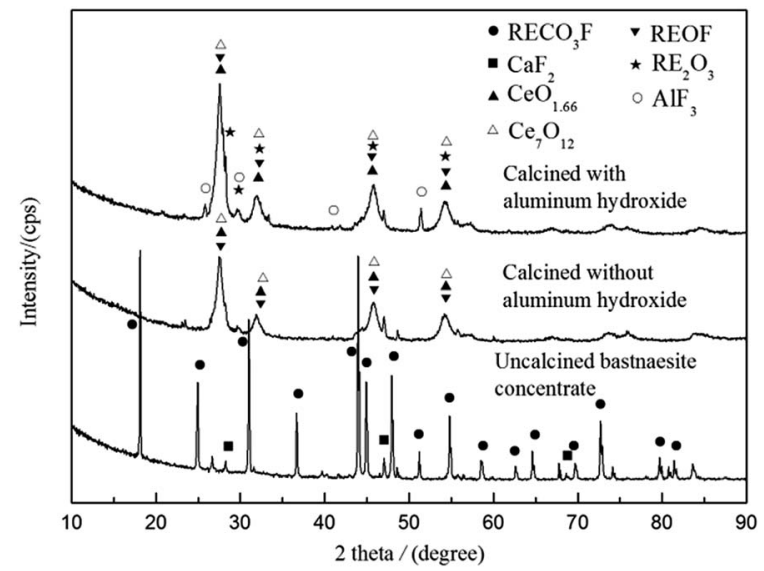

Fig. 2 XRD patterns of bastnaesite concentrate before and after calcination (calcination temperature $500{ }^{\circ} \mathrm{C}$ and calcination time $1 \mathrm{~h}$ ).

$510{ }^{\circ} \mathrm{C}$ could be attributed to the decomposition of bastnaesite, and the mass loss was due to the release of $\mathrm{CO}_{2}$. There were two endothermic peaks on the TG-DSC curves of mixed ores added with aluminum hydroxide in the temperature ranges of $225-300{ }^{\circ} \mathrm{C}$ and $420-520{ }^{\circ} \mathrm{C}$, respectively. The endothermic peak around $225-300{ }^{\circ} \mathrm{C}$ could be attributed to the dehydration of aluminum hydroxide, and the endothermic peak around $420-520{ }^{\circ} \mathrm{C}$ was for the decomposition of bastnaesite.

In order to study the decomposition reactions in calcination process, calcined ore obtained was analyzed by XRD, and the patterns are presented in Fig. 2. As shown in Fig. 2, the main phase in the bastnaesite concentrate was $\operatorname{RECO}_{3} \mathrm{~F}$ and $\mathrm{CaF}_{2}$. After calcined in the air, the peaks of $\mathrm{RECO}_{3} \mathrm{~F}$ mostly disappeared, indicating that the bastnaesite decomposed completely. The calcined ore without aluminum hydroxide mainly contained $\mathrm{REOF}, \mathrm{CeO}_{1.66}$ and $\mathrm{Ce}_{7} \mathrm{O}_{12}$, but the calcined ore with aluminum hydroxide mainly contained $\mathrm{REOF}, \mathrm{RE}_{2} \mathrm{O}_{3}$, $\mathrm{CeO}_{1.66}, \mathrm{Ce}_{7} \mathrm{O}_{12}$, and the new phase of $\mathrm{AlF}_{3}$. The $\mathrm{Ce}^{3+}$ could be oxidized to $\mathrm{Ce}^{4+}$ in the calcination process; however, the oxygen

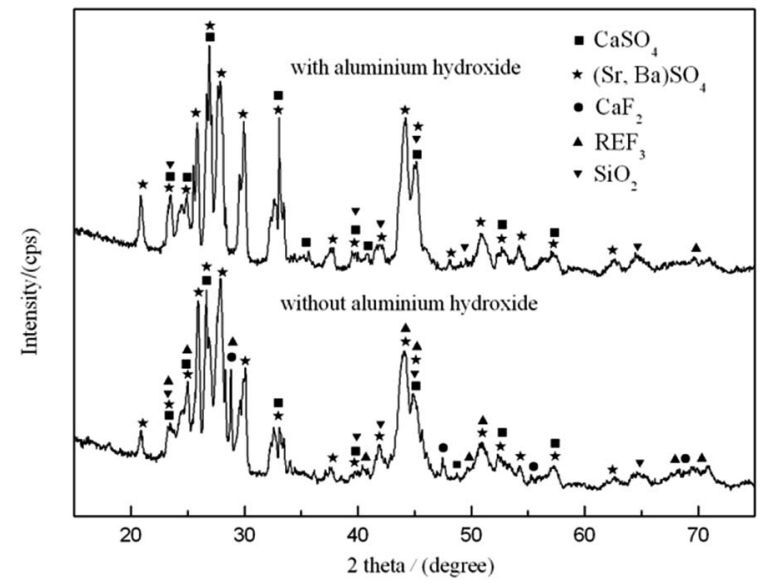

Fig. 3 XRD patterns of leaching residues (sulfuric acid concentration $3 \mathrm{~mol} \mathrm{~L}{ }^{-1}$, leaching temperature $90^{\circ} \mathrm{C}$ and leaching time $1 \mathrm{~h}$ ). 
Table 3 The main chemical composition of the leaching residue of calcined bastnaesite concentrate (wt\%)

\begin{tabular}{llllllll}
\hline Component & $\mathrm{SrO}$ & $\mathrm{SO}_{3}$ & $\mathrm{BaO}$ & $\mathrm{CaO}$ & $\mathrm{F}$ & $\mathrm{RE}_{x} \mathrm{O}_{y}$ & $\mathrm{SiO}_{2}$ \\
Content/\% & 18.82 & 18.41 & 15.50 & 13.63 & 12.17 & 8.71 & 2.52
\end{tabular}

Table 4 The main chemical composition of the leaching residue of calcined bastnaesite concentrate with aluminum hydroxide (wt\%)

\begin{tabular}{llllllll}
\hline Component & $\mathrm{SrO}$ & $\mathrm{SO}_{3}$ & $\mathrm{CaO}$ & $\mathrm{BaO}$ & $\mathrm{SiO}_{2}$ & $\mathrm{~F}$ & $\mathrm{RE}_{x} \mathrm{O}_{y}$ \\
Content/\% & 25.74 & 24.75 & 17.86 & 13.59 & 3.45 & 0.51 & -
\end{tabular}

content in calcination atmosphere was not enough to oxidize $\mathrm{Ce}_{2} \mathrm{O}_{3}$ to $\mathrm{CeO}_{2}$ completely, resulting in the formation of the mixed-valent cerium oxides $\mathrm{CeO}_{1.66}$ and $\mathrm{Ce}_{7} \mathrm{O}_{12} \cdot{ }^{21-23}$ Aluminum hydroxide began to dehydrate at the temperature above $225^{\circ} \mathrm{C}$, and transformed into activated aluminum oxide which could capture fluoride in REOF. ${ }^{24}$ The appearance of $\mathrm{RE}_{2} \mathrm{O}_{3}$ and $\mathrm{AlF}_{3}$ implied that $\mathrm{Al}_{2} \mathrm{O}_{3}$ reacted with $\mathrm{REOF}$, and the fluorine was fixed by forming $\mathrm{AlF}_{3}$ rather than discharged into the environment. Combining TG-DSC and XRD analyses, the main reactions are inferred as follows: ${ }^{22}$

$$
\begin{gathered}
2 \mathrm{Al}(\mathrm{OH})_{3} \rightarrow \mathrm{Al}_{2} \mathrm{O}_{3}+3 \mathrm{H}_{2} \mathrm{O} \uparrow \\
3 \mathrm{REFCO}_{3} \rightarrow \mathrm{REF}_{3}+\mathrm{RE}_{2} \mathrm{O}_{3}+3 \mathrm{CO}_{2} \uparrow \\
\mathrm{REF}_{3}+\mathrm{RE}_{2} \mathrm{O}_{3} \rightarrow 3 \mathrm{REOF} \\
3 \mathrm{CeOF}+1 / 2 \mathrm{O}_{2} \rightarrow 2 \mathrm{CeO}_{2} \cdot \mathrm{CeF}_{3} \\
\mathrm{Ce}_{2} \mathrm{O}_{3}+0.16 \mathrm{O}_{2} \rightarrow 2 \mathrm{CeO}_{1.66} \\
14 \mathrm{Ce}_{2} \mathrm{O}_{3}+3 \mathrm{O}_{2} \rightarrow 4 \mathrm{Ce}_{7} \mathrm{O}_{12} \\
6 \mathrm{REOF}+\mathrm{Al}_{2} \mathrm{O}_{3} \rightarrow 2 \mathrm{AlF}_{3}+3 \mathrm{RE}_{2} \mathrm{O}_{3}
\end{gathered}
$$

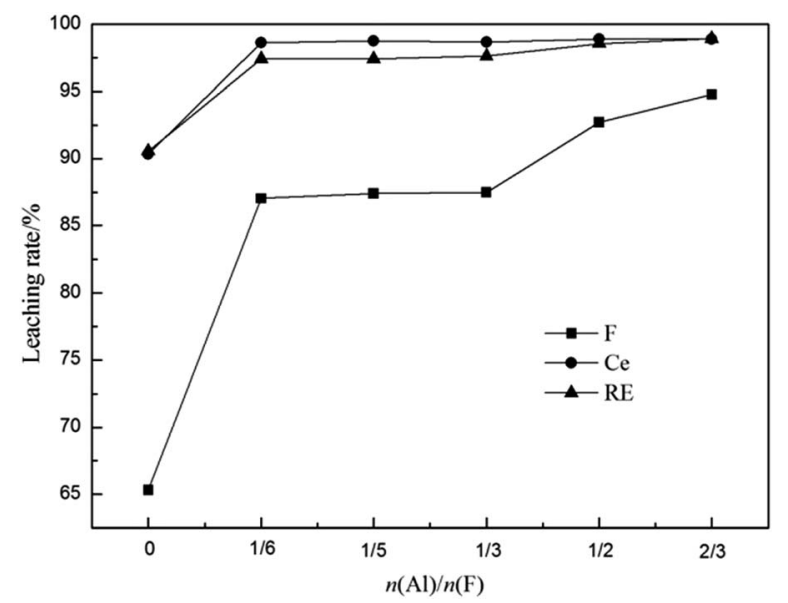

Fig. 4 Effect of $n(\mathrm{Al}) / n(\mathrm{~F})$ on leaching rates of fluorine and REs (calcination temperature $500{ }^{\circ} \mathrm{C}$, calcination time $1 \mathrm{~h}$, sulfuric acid concentration $3 \mathrm{~mol} \mathrm{~L}^{-1}$, leaching temperature $90{ }^{\circ} \mathrm{C}$ and leaching time $1 \mathrm{~h}$ ).

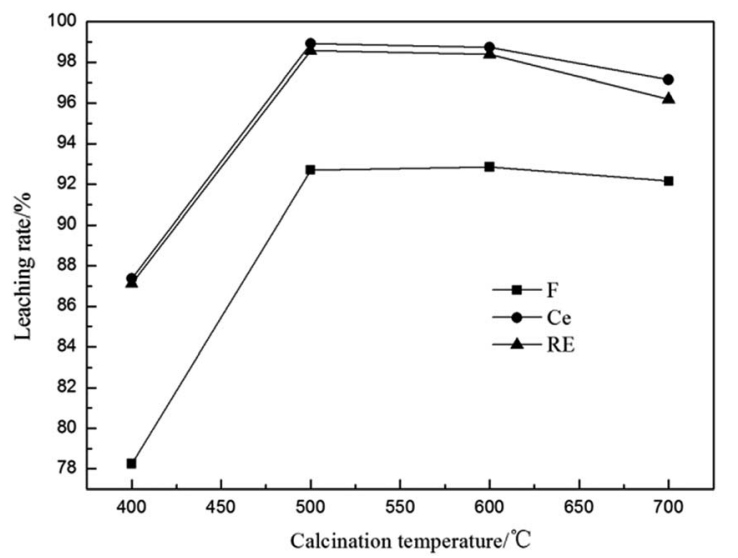

Fig. 5 Effect of calcination temperature on leaching rates of fluorine and REs $(n(\mathrm{Al}) / n(\mathrm{~F}) 1 / 2$, calcination time $1 \mathrm{~h}$, sulfuric acid concentration $3 \mathrm{~mol} \mathrm{~L}-1$, leaching temperature $90^{\circ} \mathrm{C}$ and leaching time $1 \mathrm{~h}$ ).

\subsection{Leaching of fluorine and REs}

3.2.1 Mechanism of leaching process. Leaching residues of calcined bastnaesite concentrate with and without aluminum hydroxide were also analyzed by $\mathrm{XRD}$, and the patterns are performed in Fig. 3. It is demonstrated that the leaching residue without aluminum hydroxide mainly contained $\mathrm{BaSO}_{4}, \mathrm{SrSO}_{4}$, $\mathrm{CaSO}_{4}, \mathrm{REF}_{3}, \mathrm{CaF}_{2}$ and $\mathrm{SiO}_{2}$, while the leaching residue with aluminum hydroxide mainly contained $\mathrm{BaSO}_{4}, \mathrm{SrSO}_{4}, \mathrm{CaSO}_{4}$ and $\mathrm{SiO}_{2}$. The main chemical compositions of leaching residues of calcined bastnaesite concentrate with and without aluminum hydroxide are listed in Tables 3 and 4 . It indicates that the adding of aluminum hydroxide could greatly promote the leaching of insoluble fluorides and REs. The unreacted $\mathrm{Al}_{2} \mathrm{O}_{3}$ could ionize out $\mathrm{Al}^{3+}$ ions in sulfuric acid condition. Due to the hard-hard combination of the soft-hard acid base (SHAB) concept, the $\mathrm{Al}^{3+}$ ions have good affinity with $\mathrm{F}^{-}$anions to form $\left[\mathrm{AlF}_{n}\right]^{(3-n)}$ complex ions, ${ }^{25,26}$ which will promote the dissolution of $\mathrm{CaF}_{2}$ and $\mathrm{REF}_{3}$, and thus reduce the discharge of fluorinecontaining waste. The most possible reactions during the process can be provided as follows:

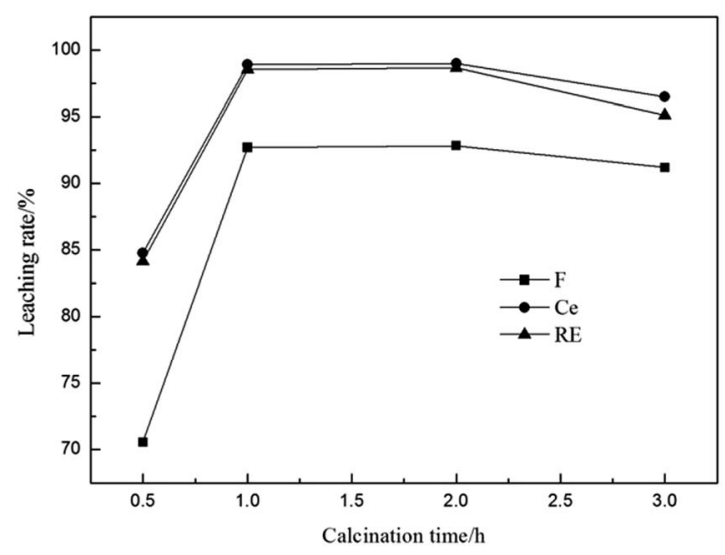

Fig. 6 Effect of calcination time on leaching rates of fluorine and REs $\left(n(\mathrm{Al}) / n(\mathrm{~F}) 1 / 2\right.$, calcination temperature $500^{\circ} \mathrm{C}$, sulfuric acid concentration $3 \mathrm{~mol} \mathrm{~L}^{-1}$, leaching temperature $90^{\circ} \mathrm{C}$ and leaching time $1 \mathrm{~h}$ ). 


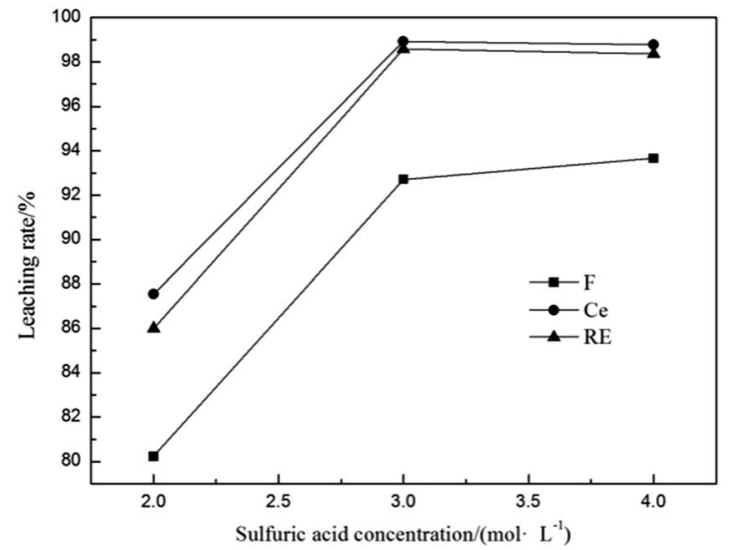

Fig. 7 Effect of sulfuric acid concentration on leaching rates of fluorine and $\mathrm{REs}\left(n(\mathrm{Al}) / n(\mathrm{~F}) 1 / 2\right.$, calcination temperature $500{ }^{\circ} \mathrm{C}$, calcination time $1 \mathrm{~h}$, leaching temperature $90^{\circ} \mathrm{C}$ and leaching time $1 \mathrm{~h}$ ).

$$
\begin{gathered}
\mathrm{Al}_{2} \mathrm{O}_{3}+6 \mathrm{H}^{+} \rightarrow 2 \mathrm{Al}^{3+}+3 \mathrm{H}_{2} \mathrm{O} \\
n \mathrm{REOF}+\mathrm{RE}_{2} \mathrm{O}_{3}+\mathrm{CeO}_{2}+(2 n+10) \mathrm{H}^{+}+\mathrm{Al}^{3+}= \\
{\left[\mathrm{AlF}_{n}\right]^{(3-n)}+\mathrm{Ce}^{4+}+(n+2) \mathrm{RE}^{3+}+(n+5) \mathrm{H}_{2} \mathrm{O}} \\
n \mathrm{CaF}_{2}+2 \mathrm{Al}^{3+}+n \mathrm{H}_{2} \mathrm{SO}_{4} \rightarrow 2\left[\mathrm{AlF}_{n}\right]^{(3-n)}+n \mathrm{CaSO}_{4} \downarrow+2 n \mathrm{H}^{+} \\
n \mathrm{REF}_{3}+3 \mathrm{Al}^{3+} \rightarrow 3\left[\mathrm{AlF}_{n}\right]^{(3-n)}+n \mathrm{RE}^{3+} \\
\mathrm{AlF}_{3}+\mathrm{Al}^{3+} \rightarrow \mathrm{AlF}_{2}^{+}+\mathrm{AlF}^{2+}
\end{gathered}
$$

3.2.2 Effect of $\boldsymbol{n}(\mathbf{A l}) / \boldsymbol{n}(\mathbf{F})$. The effect of $n(\mathrm{Al}) / n(\mathrm{~F})$ on the leaching rates of fluorine and REs is shown in Fig. 4. It can be seen that the leaching rates of $\mathrm{F}$, Ce and total RE were around $65.32 \%, 90.34 \%$ and $90.57 \%$ of calcined bastnaesite without additive. When the $n(\mathrm{Al}) / n(\mathrm{~F})$ was $1 / 6$, the leaching rates of $\mathrm{F}, \mathrm{Ce}$ and total RE significantly increased to $87.04 \%, 98.65 \%$ and $97.42 \%$. This is because that the defluorination reaction of REOF will accelerate the decomposition of $\mathrm{REFCO}_{3}$. Further

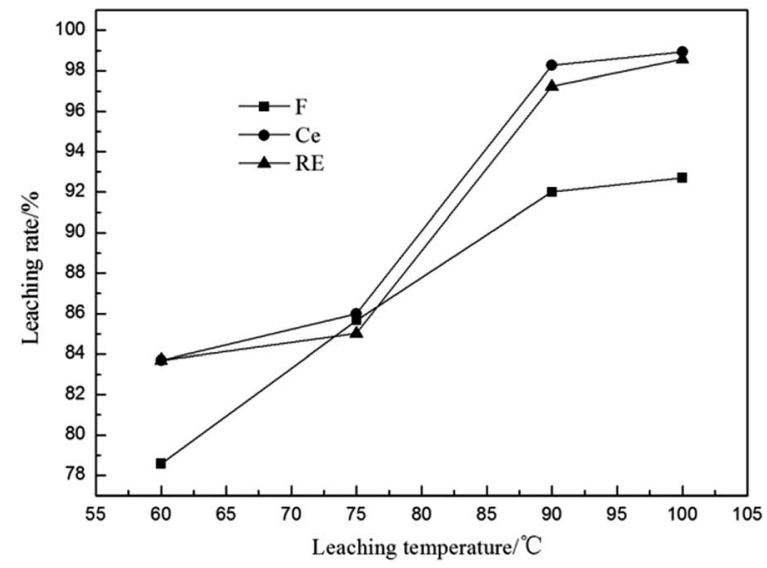

Fig. 8 Effect of leaching temperature on leaching rates of fluorine and $\mathrm{REs}\left(n(\mathrm{Al}) / n(\mathrm{~F}) 1 / 2\right.$, calcination temperature $500^{\circ} \mathrm{C}$, calcination time $1 \mathrm{~h}$, sulfuric acid concentration $3 \mathrm{~mol} \mathrm{~L}^{-1}$ and leaching time $1 \mathrm{~h}$ ).

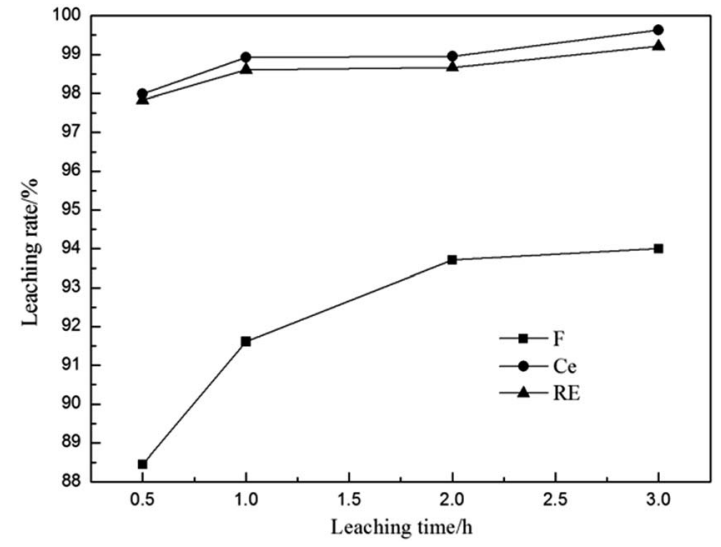

Fig. 9 Effect of leaching time on leaching rates of fluorine and REs $\left(n(\mathrm{Al}) / n(\mathrm{~F}) 1 / 2\right.$, calcination temperature $500^{\circ} \mathrm{C}$, calcination time $1 \mathrm{~h}$, sulfuric acid concentration $3 \mathrm{~mol} \mathrm{~L}^{-1}$ and leaching temperature $90^{\circ} \mathrm{C}$ ).

increase in $n(\mathrm{Al}) / n(\mathrm{~F})$, the changes of leaching rates of Ce and total RE were not obvious but the leaching rate of $\mathrm{F}$ continued to increase. The leaching rate of $\mathrm{F}$ reached $93 \%$ at the $n(\mathrm{Al}) / n(\mathrm{~F})$ of $1 / 2$. Therefore, the additive amount of $\mathrm{Al}(\mathrm{OH})_{3}$ is selected as $n(\mathrm{Al}) / n(\mathrm{~F})$ of $1 / 2$.

3.2.3 Effect of calcination temperature. The bastnaesite decomposes in the range of $425-560{ }^{\circ} \mathrm{C} .{ }^{27}$ It is necessary to control the appropriate reaction temperature. The effect of calcination temperature was examined as shown in Fig. 5. It is found that the leaching rates increased fast in the range of 400$500{ }^{\circ} \mathrm{C}$. Continue raising the temperature, the leaching rates of Ce and total RE had a little decrease when the temperature higher than $600{ }^{\circ} \mathrm{C}$. This is because that when the calcination temperature lower than $500{ }^{\circ} \mathrm{C}$, the bastnaesite decomposes incompletely, resulting in the low leaching rates of fluorine and REs; when the calcination temperature higher than $600^{\circ} \mathrm{C}$, the rare earth oxides have crystal transformation phenomenon which will decrease the activity of bastnaesite, ${ }^{28}$ leading to the lower leaching rate of REs. According to the results, the appropriate reaction temperature is $500-600{ }^{\circ} \mathrm{C}$. Taking into account the energy efficiency, a calcination temperature of $500{ }^{\circ} \mathrm{C}$ is selected.

3.2.4 Effect of calcination time. The effect of calcination time on the leaching rates of fluorine and REs is shown in Fig. 6. The results show that the leaching rates of fluorine and REs remarkably increased with the increase of calcination time and reached the maximum values at $1 \mathrm{~h}$, at which the leaching rates of $\mathrm{F}$, Ce and total $\mathrm{RE}$ were $92.71 \%, 98.92 \%$ and $98.61 \%$. However, the leaching rates had a little decline when the

Table 5 Concentrations of $\mathrm{F}^{-}, \mathrm{Al}^{3+}, \mathrm{Ce}^{4+}$ and $\mathrm{RE}^{3+}$ in leaching solution

\begin{tabular}{lllll}
\hline Extraction times & $\begin{array}{l}{\left[\mathrm{F}^{-}\right]} \\
(\mathrm{mol} \mathrm{L}\end{array}$ & $\begin{array}{l}{\left[\mathrm{Al}^{3+}\right]} \\
(\mathrm{mol} \mathrm{L}\end{array}$ & $\begin{array}{l}{\left[\mathrm{Ce}^{4+}\right]} \\
\left(\mathrm{mol} \mathrm{L}^{-1}\right)\end{array}$ & $\begin{array}{l}{\left[\mathrm{RE}^{3+}\right]} \\
\left(\mathrm{mol} \mathrm{L}^{-1}\right)\end{array}$ \\
\hline 0 & & & & \\
1 & 0.58 & 0.30 & 0.28 & 0.21 \\
2 & 0.56 & 0.30 & 0.02 & 0.21 \\
3 & 0.56 & 0.29 & - & 0.08 \\
& 0.56 & 0.29 & - & -
\end{tabular}




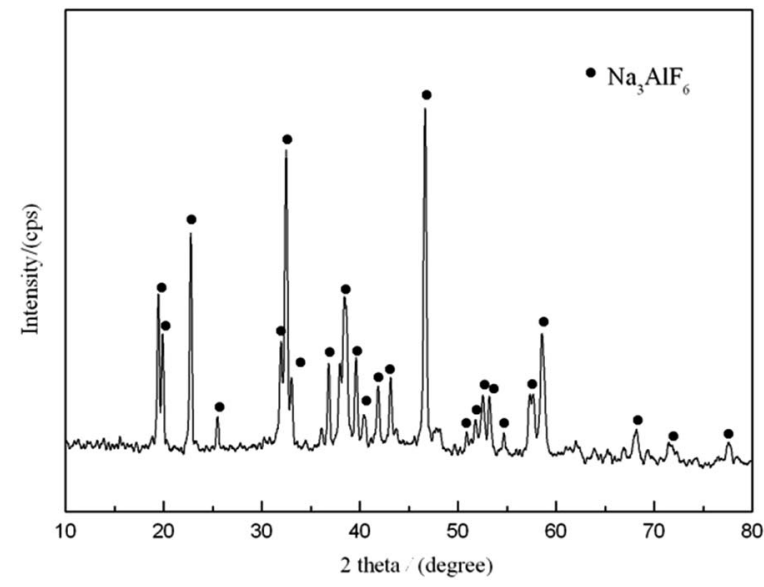

Fig. 10 XRD pattern of the prepared cryolite.

calcination time was longer than $2 \mathrm{~h}$, which may be due to the generation of more insoluble fluosilicate. ${ }^{29}$ Therefore, a calcination time of $1 \mathrm{~h}$ can be selected.

3.2.5 Effect of sulfuric acid concentration. The effect of sulfuric acid concentration on the leaching rates of fluorine and REs is shown in Fig. 7. It is seen from Fig. 7 that both the leaching rates of $\mathrm{F}$, Ce and total RE increased with the increase in sulfuric acid concentration, and had no beneficial effect with acid concentration higher than $3 \mathrm{~mol} \mathrm{~L}^{-1}$. Excessively low acidity in the leaching solution can not react with calcined ore thoroughly, leading to the low leaching rates of fluorine and REs. However, excessively high acidity in the leaching solution is unfavorable for the subsequent extraction process. ${ }^{1}$ Therefore, a concentration of $3 \mathrm{~mol} \mathrm{~L}^{-1}$ is selected as the optimum acidity of leaching solution.

3.2.6 Effect of leaching temperature. The effect of leaching temperature on the leaching rates of fluorine and REs is shown in Fig. 8. The results showed that the higher the temperature was, the higher the leaching rates of $\mathrm{F}$, Ce and total $\mathrm{RE}$ were. The leaching rate of $\mathrm{F}$ was promoted from $78.58 \%$ to $92.00 \%$ with the temperature increased from $60{ }^{\circ} \mathrm{C}$ to $90{ }^{\circ} \mathrm{C}$ while the

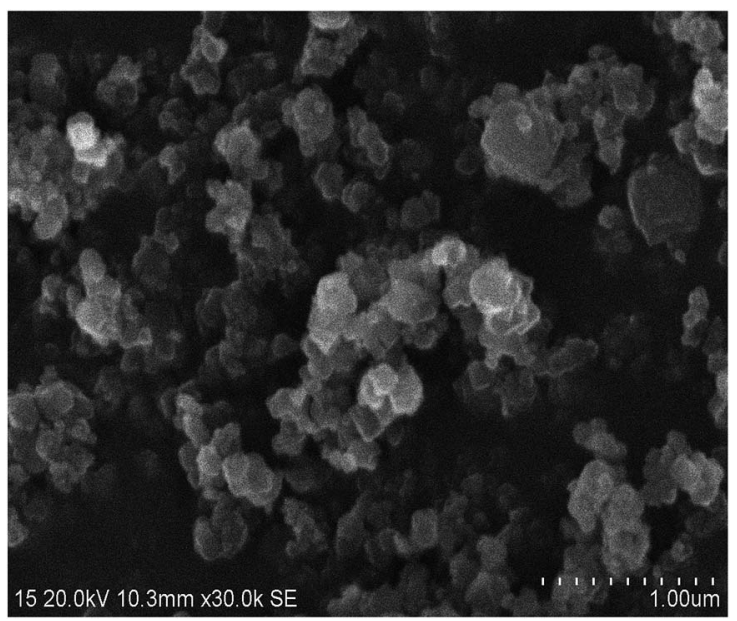

Fig. 11 SEM photograph of the prepared cryolite.
Table 6 Recovery rates of fluoride and aluminum

\begin{tabular}{lcl}
\hline & Fluoride & Aluminum \\
\hline$\left[\mathrm{F}^{-}\right]$and $\left[\mathrm{Al}^{3+}\right]$ of raffinate/(mol L & \\
Volume of raffinate/(L) & 0.56 & 0.29 \\
$\begin{array}{l}\text { Amount of supplemental sodium } \\
\text { fluoride/(mmol) }\end{array}$ & 0.10 & 0.10 \\
{$\left[\mathrm{~F}^{-}\right]$and $\left[\mathrm{Al}^{3+}\right]$ of supernatant } & 35.0 & - \\
solution $/\left(\mathrm{mmol} \mathrm{L}^{-1}\right)$ & 37.1 & 7.60 \\
$\begin{array}{l}\text { Volume of supernatant solution/(L) } \\
\text { Recovery rate/(\%) }\end{array}$ & 0.10 & 0.10 \\
& 96.33 & 97.38
\end{tabular}

leaching rates of Ce and total RE only increased quickly with the temperature higher than $75^{\circ} \mathrm{C}$, and both had no obvious rising when the leaching temperature was over $90{ }^{\circ} \mathrm{C}$. Therefore, a leaching temperature of $90{ }^{\circ} \mathrm{C}$ is chosen as the optimal temperature for the leaching experiments.

3.2.7 Effect of leaching time. The effect of leaching time on the leaching rates of fluorine and REs is shown in Fig. 9. It is found from Fig. 9 that the leaching rates of Ce and total RE were nearly $98 \%$ at $0.5 \mathrm{~h}$ and had no obvious increase with the prolonging of leaching time. However, the leaching rate of $\mathrm{F}$ increased significantly with the reaction. The difference in the leaching speed of fluorine and REs proves that the fluorine is not leached out entirely with rare earths. The leaching rate of $F$ could be above $90 \%$ after leaching for $1 \mathrm{~h}$.

\subsection{Separation of fluorine and REs}

The obtained sulfuric acid leaching solution contained $0.58 \mathrm{~mol}$ $\mathrm{L}^{-1} \mathrm{~F}^{-}, 0.30 \mathrm{~mol} \mathrm{~L}^{-1} \mathrm{Al}^{3+}, 0.28 \mathrm{~mol} \mathrm{~L}^{-1} \mathrm{Ce}^{4+}, 0.21 \mathrm{~mol} \mathrm{~L}^{-1} \mathrm{RE}^{3+}$, $1.50 \mathrm{~mol} \mathrm{~L}^{-1} \mathrm{H}^{+}$, etc. The $\mathrm{Ce}^{4+}$ was extracted by mixing equal volumes of leaching solution and $1 \mathrm{~mol} \mathrm{~L}^{-1} \mathrm{HDEHP}$, then the $\mathrm{Ce}^{4+}$-absence solution was obtained. The $\mathrm{RE}^{3+}$ concentrate was extracted by mixing equal volumes of HDEHP and the resulting $\mathrm{Ce}^{4+}$-absence solution which had been adjusted to $\mathrm{pH} 3.8$ by ammonia. The results are presented in Table 5. It is found that after three times of extraction, the $\mathrm{Ce}^{4+}$ and $\mathrm{RE}^{3+}$ were extracted into organic phase and almost all of the $\mathrm{F}^{-}$and $\mathrm{Al}^{3+}$ were left in raffinate. This is because that fluoride and aluminum mainly exist as $\left[\mathrm{AlF}_{n}\right]^{(3-n)}$ complex in acidic solution, ${ }^{26}$ and the $\left[\mathrm{AlF}_{n}\right]^{(3-n)}$ complex cannot be extracted by HDEHP, which is leading to the separation of fluorine and REs.

\subsection{Recovery of fluorine}

The raffinate containing $0.56 \mathrm{~mol} \mathrm{~L}^{-1} \mathrm{~F}^{-}$and $0.29 \mathrm{~mol} \mathrm{~L}^{-1} \mathrm{Al}^{3+}$ which mainly exist as aluminum fluoride complexes $\left[\mathrm{AlF}_{n}\right]^{(3-n)}$ was used to produce cryolite so as to recover the fluorine resource in bastnaesite. It is known that the ratio of $\mathrm{F} / \mathrm{Al}$ in aluminum fluoride complex $\left[\mathrm{AlF}_{n}\right]^{(3-n)}$ greatly depends on the contents of fluoride and aluminum. In order to recover the fluoride and aluminum in the raffinate as much as possible, the sodium fluoride was added to adjust the $\mathrm{F} / \mathrm{Al}$ and $\mathrm{Na} / \mathrm{Al}$ molar ratios, and the sodium hydroxide or ammonia was added to adjust the $\mathrm{pH}$ to around 4.5-5.0. The reaction temperature was controlled within $80-90{ }^{\circ} \mathrm{C}$. The solubility of $\mathrm{Na}_{3} \mathrm{AlF}_{6}$ is $4 \times$ 
$10^{-10},{ }^{30}$ making it easy to precipitate from solution. Fig. 10 shows the XRD pattern of the product. The characteristic peaks of $\mathrm{Na}_{3} \mathrm{AlF}_{6}$ were observed and the prepared product was found to be monoclinic phase cryolite. Fig. 11 gives the SEM image of the product. It is found that the obtained cryolite consisted of even and uniform granules with an average diameter of 1-2 $\mu \mathrm{m}$. The results in Table 6 showed that the high recovery rates of fluoride and aluminum greater than $96 \%$ could be obtained, indicating that the preparation of cryolite is an effective method to recover fluorine resource in bastnaesite.

$$
\begin{gathered}
{\left[\mathrm{AlF}_{n}\right]^{(3-n)}+(6-n) \mathrm{F}^{-} \rightarrow \mathrm{AlF}_{6}{ }^{3-}} \\
3 \mathrm{Na}^{+}+\mathrm{AlF}_{6}{ }^{3-} \rightarrow \mathrm{Na}_{3} \mathrm{AlF}_{6} \downarrow
\end{gathered}
$$

\section{Conclusions}

In order to solve the problems of fluorine loss and contamination, and recover the fluorine resource in bastnaesite, a new clean process of decomposing bastnaesite with aluminum hydroxide followed by sulfuric acid leaching was proposed. In the oxidation calcination process, fluorine could be taken up by $\mathrm{Al}_{2} \mathrm{O}_{3}$, preventing the discharge of fluorine. After calcination, leaching for calcined ore was performed with dilute sulfuric acid. Aluminum could promote the dissolution of $\mathrm{CaF}_{2}$ and $\mathrm{REF}_{3}$ in bastnaesite. The optimum conditions were determined as $n(\mathrm{Al}) / n(\mathrm{~F}) 1 / 2$, calcination temperature $500{ }^{\circ} \mathrm{C}$, calcination time $1 \mathrm{~h}$, sulfuric acid concentration $3 \mathrm{~mol} \mathrm{~L}^{-1}$, leaching temperature $90{ }^{\circ} \mathrm{C}$ and leaching time $1 \mathrm{~h}$, at which the leaching rates of $\mathrm{F}$, Ce and total RE reached $92.71 \%, 98.92 \%$ and $98.61 \%$. Fluorine could be separated from REs after extraction process, and was recovered as $\mathrm{Na}_{3} \mathrm{AlF}_{6}$ with the recovery rates of fluoride and aluminum greater than $96 \%$. This technology has an important practical significance to further develop rare earth metallurgical industry and protect environment.

\section{Acknowledgements}

The financial aids from the key program of National Natural Science Foundation of China (NSFC: 50934004), National Natural Science Foundation of China (51274061), Major State Basic Research Development Program of China (973 Program: 2012CBA01205) and Fundamental Research Supporting Project of Northeastern University (N110602006) are gratefully acknowledged.

\section{References}

1 W. Y. Wu, Rare Earth Metallurgy, Chemical Industry Press, Beijing, 2005, p. 56.

2 Y. Kanazawa and M. Kamitani, J. Alloys Compd., 2006, 408412, 1339-1343.

3 W. P. Liu, X. M. Wang, Z. X. Wang and J. D. Miller, Miner. Eng., 2016, 85, 17-22.
4 S. C. Sun, Z. Y. Wu, B. Gao, X. Bian, W. Y. Wu and G. F. Tu, J. Rare Earths, 2007, 25(4), 508-511.

5 X. W. Huang, Z. Q. Long, H. W. Li, W. J. Ying, G. C. Zhang and X. X. Xue, J. Rare Earths, 2005, 23(1), 1-4.

6 G. C. Zhu, J. Tian, R. A. Chi and S. M. Xu, Chemistry, 2000, 63(12), 6-11.

7 Q. W. Zhang and F. Saito, Hydrometallurgy, 1998, 47(2), 231241.

8 Y. Abdulkerim, O. Abdullah and G. Ismail, Hydrometallurgy, 2003, 68(1-3), 195-202.

9 S. L. Zhao, C. G. He, Z. J. Cao, Y. Liu and F. Zhao, Chin. Rare Earths, 2003, 24(4), 32-35.

10 Y. K. Huang, T. A. Zhang, Z. H. Dou, J. Liu and F. F. Tang, J. Rare Earths, 2014, 32(11), 1043-1047.

11 T. Xu and H. Q. Peng, J. Rare Earths, 2009, 27(6), 1096-1102. 12 A. Bhatnagara, E. Kumara and M. Sillanpää, Chem. Eng. J., 2011, 171(3), 811-840.

13 J. Qiao, C. R. Zhang, S. G. Liu and X. K. Hao, Chin. Rare Earths, 1997, 18(3), 64-67.

14 R. M. Sawant, R. K. Rastogi, M. A. Mahajan and N. K. Chaudhuri, Talanta, 1996, 43(1), 89-94.

15 Z. F. Zhang, F. Q. Guo, S. L. Meng, Q. Jia, H. F. Li and D. Q. Li, Ind. Eng. Chem. Res., 2010, 49, 6184-6188.

16 G. C. Zhu, J. Tian, R. A. Chi, S. M. Xu and Z. G. Zhang, Chin. Rare Earths, 2001, 22(3), 30-33.

17 Z. G. Liu, Q. S. Yang, L. S. Liu, S. S. Guo, B. Z. Chen, X. J. Wei and A. N. Hu, Chin. Rare Earths, 2004, 25(2), 20-25.

18 L. S. Wang, C. M. Wang, Y. Yu, X. W. Huang, Z. Q. Long, Y. K. Hou and D. L. Cui, J. Hazard. Mater., 2012, 209210(4), 77-83.

19 H. Y. Fu, Y. Y. Wei, Y. Li and J. G. He, J. Chin. Soc. Rare Earths, 2013, 31(4), 393-398.

20 Z. Akdeniz, Z. Cicek and M. P. Tosi, Chem. Phys. Lett., 1999, 308(5-6), 479-485.

21 E. A. Kümmerle and G. Heger, J. Solid State Chem., 1999, 147(2), 485-500.

22 Y. Yang, S. C. Sun, X. P. Zhu, W. Jia and G. F. Tu, J. Chin. Soc. Rare Earths, 2015, 33(1), 95-100.

23 M. Zinkevich, D. Djurovic and F. Aldinger, Solid State Ionics, 2006, 177(177), 989-1001.

24 Z. H. Peng, Q. F. Li and Q. S. Zhou, Light Metals, 2010, 5, 1618.

25 B. R. Martin, Coord. Chem. Rev., 1996, 149(1), 23-32.

26 B. J. Plankey and H. H. Patterson, Environ. Sci. Technol., 1986, 20(2), 160-165.

27 W. Y. Wu, X. Bian, Z. Y. Wu, S. C. Sun and G. F. Tu, Trans. Nonferrous Met. Soc. China, 2007, 17(4), 864-868.

28 M. H. Wang, M. Zeng, L. S. Wang, J. H. Zhou, D. L. Cui, Q. G. Wang, R. G. Weng and X. S. Chen, J. Chin. Soc. Rare Earths, 2013, 31(2), 148-153.

29 J. Zhou, C. H. Yan and C. S. Liao, Chin. Rare Earths, 1998, 19(3), 9-17.

30 M. Kumar, M. N. Babu, T. R. Mankhand and B. D. Pandey, Hydrometallurgy, 2010, 104(2), 304-307. 